\title{
On a method of producing lights and shades in equal perfection in Daguerreotype pictures
}

\section{Belfield Lefevre \& Leon Foucault}

To cite this article: MM. Belfield Lefevre \& Leon Foucault (1847) On a method of producing lights and shades in equal perfection in Daguerreotype pictures, Philosophical Magazine Series 3, 30:200, 213-214, DOI: $10.1080 / 14786444708645643$

To link to this article: http://dx.doi.org/10.1080/14786444708645643

曲 Published online: 30 Apr 2009.

Submit your article to this journal $\sqsubset \pi$

Џll Article views: 2

Q View related articles $\widetilde{ }$ 
If however two equivalents of sulphuric acid and one equivalent of alcohol be employed, circumstances are altered; sulphovinic acid is alwaye formed; and still more, the proportion of sulphovinic acid is always the same, whether the acid be poured into the alcohol or the reverse ; whether metallic vessels be used or not; and whether they are or are not cooled. The whole of the acid and alcohol do not however combine; the reaction does not take place on much more than half of the mixture, for not more than 54 of sulphovinic acid can be formed from 100 of sulphuric. This proportion does not change by prolonging the contact, or even by the application of a heat of $212^{\circ} \mathrm{F}$. continued for several hours; the capacity of saturation of the acid mixture remains the same. In heating to $212^{\circ}$, the volume is scarcely diminished; it follows, therefore, that the alcohol which is not changed into sulphovinic acid must be retained by a peculiar affinity.-Ann. de Ch. et de Phys., Fevrier 1847.

ON $\triangle$ METHOD OF PRODUCING LIGHTS AND SHADES IN EQUAL PERFECTION IN DAGUERREOTYPE PICTURES. BY MM. BELFIELD LEFEVRE AND LEON FOUCAULT.

It was observed soon after $M$. Daguerre had made known his wonderful discovery, that the iodized plate was not suited for producing a perfect image of every object, but that if there was a great variety of light and shade, $i$. $e$. very light and very dark parts, they would not be simultaneously brought out with correctness : one of these two alternatives must be chosen; either to stop the process when the light parts of the picture are brought out (in which case the dark parts will not be clearly distinguishable), or to allow the light to act for a longer time, in order to render the dark parts distinct; but in this case the light parts will be rendered indistinct, or, as it is called, burnt.

These evils have fortunately been remedied by the employment of certain substances, which not only allow of the operation being performed with greater rapidity, but also produce sensitive surfaces capable of receiving a much greater variety of tints. These are, however, far from being perfect; and therefore if any process could be discovered which would bring out the light and dark parts of the picture with equal distinctness, without increasing the sensitiveness of the plates, it would be advisable to have recourse to it in certain cases. If the operator knows how to work well upon these different sensitive surfaces, without confining himself exclusively to the most sensitive, he will be able to produce any effect desired; for instance, if requisite, he will moderate the intensity of the rays of the sun bearing upon objects of inadequate reflective powers, or heighten the tone of a picture.

With a view to facilitate the attainment of good results, $\mathrm{Mr}$. Belfield and myself determined on making known a new mode of preparing the sensitive surfaces, the effect of which is to impart to the plates the property above-mentioned, and which assimilates them to the human retina. 
Our method requires the employment of iodine and bromine, and is easily performed by persons who are accustomed to employ those substances separately. It consists in polishing and iodizing the plate in the ordinary manner, and afterwards causing it, by any convenient means, to absorb three times as much vapour of bromine as is usually thought sufficient to render the plates as sensitive as possible. Whilst the ordinary quantity of bromine does not visibly alter the tint of the iodized layer, that which we recommend causes it to assume a deep bluish violet tint.

The sensihility of the plates thus surcharged with bromine is re. duced to a third of what it would be if the ordinary quantity only were used; but at the same time they are rendered capable of producing a perfect picture of subjects presenting the greatest variety of shade. This will be seen by inspecting a small picture, presented herewith, which was produced when the sun was shining. There will be perceived the clouds in the sky, white houses, with the shadows well-defined, and trees, the foliage of which is delineated much in the same manner as if executed by an artist.

We recommend the ordinary quantity of bromine to be exactly tripled; as if less than this quantity be used, the picture will not be properly brought out; and if more than this quantity were used, the mercury would not be properly condensed and the image would not be so well-defined.

This new property, communicated to the iodized plates by an excess of bromine, may be very usefully applied; and besides, as it appeared to us that this statement might be useful to the chemical world, we have been induced to make this communication to the Academy.-Comptes Rendus des Séances de l'Académie des Sciences, (as inserted in the London Journal.)

OBSERVATIONS ON THE EXPERIMENTS OF MESSRS. FOUCAULT

AND FIZEAU, RELATIVE TO THE ACTION OF THE RL'D RAYS UPON DAGUERREOTYPE PLATES. BY M. EDMOND BECQUEREL.

Messrs. Foucault and Fireau, at the sitting of the Academy on the 5th inst. (October 1846), presented some observations concerning the action of the red rays upon Daguerreotype plates, from which it would appear that the least refrangible part of the solar spectrum acts upon the iodide of silver in an inverse manner to the most refrangible portion. As it appears that these gentlemen are not acquainted with the experiments which have been made during the last few years on this subject, and as the results stated by them do not appear to me to lead to the conclusions which they deduce, I take the liberty of submitting some remarks thereon to the Acaderny.

Dr. Draper (Philosophical Magazine, Nov. 1842), on examining the image produced by the action of the spectrum upon iodized plates of silver, made known, before these gentlemen, the existence of pro. tecting rays modifying the influence of the solar rays, and even acting negatively upon the iodide of silver. Sir J. F. W. Herschel examined the pictures on that occasion, and in a very interesting experiment 